\title{
Cancer Incidence in Nepal: A Three-Year Trend Analysis 2013-2015
}

\author{
Gambhir Shrestha ${ }^{1}$, Prakash Neupane ${ }^{2}$, Nirmal Lamicchane ${ }^{3}$, Bijaya \\ Chandra Acharya ${ }^{4}$, Bhola Siwakoti ${ }^{5}$, Krishna Prasad Subedi ${ }^{5}$, Kishore Kumar \\ Pradhananga ${ }^{5}$, Rashmi Mulmi ${ }^{5}$
}

${ }^{1}$ Department of Community Medicine, Maharajgunj Medical Campus, Institute of Medicine, Tribhuvan University, Maharjgunj, Kathmandu, Nepal. ${ }^{2}$ Department of Surgical Oncology, Bhaktapur Cancer Hospital, Bhaktapur, Nepal. ${ }^{3}$ Urology Unit, Department of Surgical Oncology, B.P. Koirala Memorial Cancer Hospital, Bharatpur, Chitwan, Nepal. ${ }^{4}$ Gynaecology Unit, Department of Surgical Oncology, B.P. Koirala Memorial Cancer Hospital, Bharatpur, Chitwan, Nepal. ${ }^{5}$ Department of Cancer Prevention, Control and Research, B.P. Koirala Memorial Cancer Hospital, Bharatpur, Chitwan, Nepal.

\begin{abstract}
Background: Cancer is an major public health problem in the world. This study aims to present a three-year trend of cancer incidence in Nepal. Methods: This study used the three-year data of National Cancer Registry Program (NCRP) from January 2013 to December 2015. NCRP currently includes 12 major hospitals where diagnostic treatment facilities are available and represent the majority of the cases in Nepal. Descriptive analysis was used to present the demographic profile of the participants and the incidence of different topography of cancer. Age-specific and age-adjusted cancer incidence per 100,000 population were presented. Results: A total of 27,483 new cancer cases were included in the study. The age-adjusted incidence rates were $39.1,39.8$ and 41.8 per 100,000 population in the year 2013, 2014 and 2015 respectively. The most common cancer in Nepal was lung followed by cervical, breast, stomach and colorectal cancer. Among males, lung cancer was the most common followed by lip and oral cavity, stomach, colorectal cancer and leukemia and among females, cervical cancer followed by breast, lung, ovary and stomach. Conclusion: Cancer incidence is rising in Nepal and thus comprehensive policies targeting prevention, early detection, and treatment programs should be carried out.
\end{abstract}

Keywords: Epidemiology- Neoplasms- registries- prevention and control- Nepal

Asian Pac J Cancer Care, 5 (3), 145-150

\section{Introduction}

Cancer is a major public health problem and it has become one of the leading cause of deaths worldwide. Globally, nearly 18.1 million new cancer cases and 9.6 million cancer deaths occurred in 2018 with $70 \%$ deaths occurring in developing countries of the world [1]. By 2040, it is estimated that the new cases of cancer will rise to 29.5 million [1]. Increase in life expectancy, changes in lifestyle related factors like food habits, sedentary lifestyle, sexual behaviour, environmental pollution due to industrialization are mainly related to increasing the burden of cancer incidence and deaths in developing countries [2]. Likewise, low level of awareness of
Submission Date: 05/01/2020Ａcceptance Date: 07/03/2020

\footnotetext{
Corresponding Author:

Dr. Gambhir Shrestha

Department of Community Medicine, Maharajgunj Medical Campus, Institute of Medicine, Tribhuvan University, Maharjgunj, Kathmandu,

Nepal.

Email: gamvir.stha@gmail.com
}

people on cancer and low screening rate has additionally raised the burden of cancer which is especially diagnosed at a late stage. This challenges the existing healthcare system with added economic burden in health economy of especially those of low- and middle-income countries [3]. GLOBOCAN 2018 estimates that the age-standardized cancer incidence and mortality rates in Nepal to be 103.7 and 77.8 per 100,000 population in Nepal [4]. Previous studies have shown that the cancer burden in Nepal may still rise in future and poses a serious threat [5].

The National Cancer Registry Program (NCRP) of Nepal routinely collects data on cancer patients' information 
including demographics, primary tumour sites and tumour morphology from 12 major hospitals of Nepal. B.P. Koirala Memorial Cancer Hospital (BPKMCH) is responsible for collecting, evaluating and publishing national cancer statistics [6-7]. This study aimed to present the trend of 3-year registry data of new cancers registered in the NCRP between January 2013 and December 2015.

\section{Materials and Methods}

The Department of Cancer Prevention, Control and Research, BPKMCH is responsible to collect and analyze the data from 12 cancer centres for National cancer registry Program. The hospitals included are BPKMCH (Chitwan), Bhaktapur Cancer Hospital (Bhaktapur), Bir Hospital (Kathmandu), TU Teaching Hospital (Kathmandu), Kanti Children's Hospital (Kathmandu), B. P. Koirala Institute of Health Sciences (Sunsari), Manipal Teaching Hospital (Pokhara), Paropakar Maternity and Women's Hospital (Kathmandu), Patan Academy of Health Sciences (Lalitpur), Civil Service Hospital (Kathmandu), Shree Birendra Army Hospital (Kathmandu) and Nepalgunj Medical College Teaching Hospital (Nepalgunj [7]. These 12 hospitals have the diagnostic as well as treatment facilities and represent the majority of the cases in Nepal. This study used data collected by NCRP to present the trend of cancer incidence in Nepal in a three-year period from January 2013 to December 2015 [8-10]. The data were collected using a standardized semi-structured form consisting of socio-demographic characteristics, detail of diagnosis, clinical stage and treatment. In order to avoid double and multiple entries of the cases, the database was verified by name, age, sex, address, topography and morphology of cancer cases. The data were entered, cleaned, removed duplicates and analysed using in excel 2016. Descriptive analysis was used to present the demographic profile of the participants and the incidence of different topography of cancer according to the gender and their related variables. Age-specific and age-adjusted cancer incidence were also presented. For age-specific crude incidence rate, we used population data for 2013-2015 medium variant predicted by the Central Bureau of Statistics [11] and to adjust the age we used Segi World Standard Population. Cancer cases were categorized as per the international classification of disease for oncology (ICD-10). Permission was taken prior to the study from B.P. Koirala Memorial Cancer Hospital, Nepal.

\section{Results}

The total number of new cases from 12 hospitals were 8882 in 2013, 9221 in 2014 and 9851 in 2015. Out of which, 471 cases were non-Nepalese and were excluded from the analysis. The total number of new cases included in this study were 8729 in 2013, 9036 in 2014 and 9718 in 2015 . Male consists of $45 \%$ and female were $55 \%$ of the cases (Table 1). Majority of the cases were married. About 33\% of the cases were from Province 3 followed by Province $1(19 \%)$ and Province $5(15 \%)$.

\section{Top Cancer in Nepal}

The most common cancer in Nepal was lung followed by cervical cancer, breast, stomach and colorectal cancer (Table 2). The top leading cancer site among males was lung followed by lip and oral cavity, stomach, colorectal cancer and leukaemia. Likewise, among females, it was cervical uteri followed by breast, lung, ovary and stomach (Table 3).

\section{Cancer Incidence}

The incidence of cancer was seen increasing with the increase in age and the incidence was seen more in the age group 70-74 years in 2013. Similarly, the incidence was also seen increasing with age in 2014 and 2015 but it was found more in the age group 60-64 years. A similar pattern was seen in the incidence among the male population. However, the incidence increase with age in females with age group 45-49, 50-54 and 60-64 being the most common age group in the year 2013, 2014 and 2015 respectively. After this age group, the incidence in females was seen decreasing with age (Table 4).

The age-specific incidence rate (ASIR) was observed more in the age group 80 and above in overall (218 per 100,000 in 2015) and male population (303 per 100,000 in 2015) and 60-64 years in case of the female population ( 170 per 100,000 in 2015 ) in all the three-year period. The ASIR increased with increase in age. However, we also found that the ASIR decreased in the age group 75-79 years then increased in 80 and above population in both males and females. The ASIR in females also decreased in the age group 65-69 years. The total ASIR in females is more than that of males in 2013-2015. The ASIRs in age groups less than 30 years and more than 60 years were more than in males than females. The female ASIR increased in consecutive years but slightly decreased in males in the year 2014 (Table 5). Similarly, with age adjustment, the incidence rate in the total population was found to be increasing in consecutive years (39.1, 39.8 and 41.8 per 100,000 in the year 2013, 2014 and 2015 respectively). However, the age-adjusted incidence rate (AAIR) among male slightly decreased in 2014 (37.0, 36.5 and 39.9 per 100,000 in 2013, 2014 and 2015). In contrast, AAIR among female increased in 2014 then slightly decreased in $2015(41.0,43.9$ and 43.4 per 100,000 in 2013, 2014 and 2015) (Figure 1).

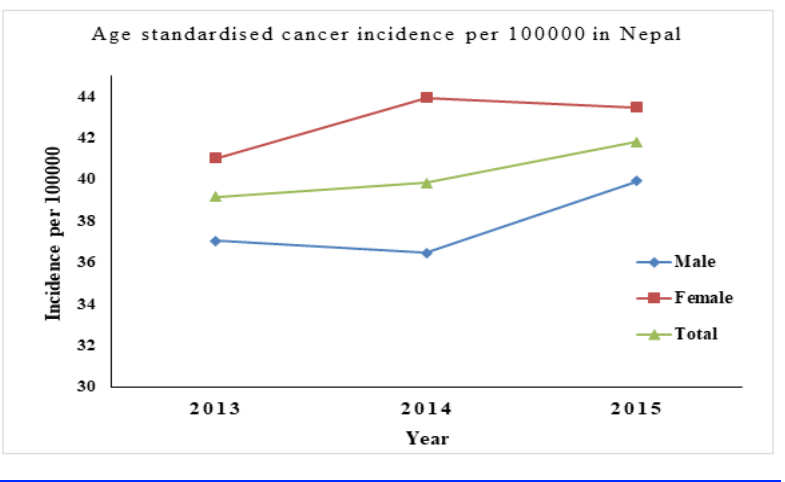

Figure 1. Age Adjusted Cancer Incidence Rate per 100,000 Populations in Nepal. 
Table 1. Characteristics of New Cancer Cases in Nepal 2013-2014

\begin{tabular}{|c|c|c|c|}
\hline \multirow[t]{2}{*}{ Characteristics } & \multicolumn{3}{|c|}{ Year n (\%) } \\
\hline & 2013 & 2014 & 2015 \\
\hline \multicolumn{4}{|l|}{ Gender } \\
\hline Male & $4,011(46.0)$ & $4,014(44.4)$ & $4,483(46.1)$ \\
\hline Female & $4,718(54.0)$ & $5,022(55.6)$ & $5,235(53.9)$ \\
\hline \multicolumn{4}{|l|}{ Marital status } \\
\hline Unmarried & $245(2.8)$ & $184(2.0)$ & $145(1.5)$ \\
\hline Married & $5,613(64.3)$ & $5,892(65.2)$ & $6064(62.4)$ \\
\hline Widow/ Divorced/ Separated & $174(2.0)$ & $183(2.0)$ & $221(2.3)$ \\
\hline Not available & $2,377(27.2)$ & $2,454(27.2)$ & $2763(28.4)$ \\
\hline Not applicable $(<15$ years) & $320(3.7)$ & $323(3.6)$ & $525(5.4)$ \\
\hline \multicolumn{4}{|l|}{ Province } \\
\hline Province 1 & $1694(19.4)$ & 1794 (19.9) & $1825(18.8)$ \\
\hline Province 2 & $1139(13.0)$ & $1203(13.3)$ & $1210(12.5)$ \\
\hline Province 3 & $2790(32.0)$ & $2919(32.3)$ & $3265(33.6)$ \\
\hline Province 4 & $1066(12.2)$ & $997(11.0)$ & $1173(12.1)$ \\
\hline Province 5 & $1304(14.9)$ & $1362(15.1)$ & $1481(15.2)$ \\
\hline Province 6 & $193(2.2)$ & $249(2.8)$ & $253(2.6)$ \\
\hline Province 7 & $310(3.6)$ & $308(3.4)$ & $340(3.5)$ \\
\hline Unknown & $233(2.7)$ & $204(2.3)$ & $171(1.8)$ \\
\hline Total & $8729(100.0)$ & $9036(100.0)$ & $9718(100.0)$ \\
\hline
\end{tabular}

Table 2. Top 10 Cancers in Nepal 2013-2015

\begin{tabular}{llc}
\hline S.N & Topography & N (\%) \\
\hline 1 & C33-34 Lung & $3737(13.60)$ \\
2 & C53 Cervix uteri & $2552(9.29)$ \\
3 & C50 Breast & $2456(8.94)$ \\
4 & C16 Stomach & $1574(5.73)$ \\
5 & C18-21 Colorectal & $1457(5.30)$ \\
6 & C00-06 Lip, oral cavity & $1426(5.19)$ \\
7 & C91-95 Leukemia & $1259(4.58)$ \\
8 & C32 Larynx & $1085(3.95)$ \\
9 & C56 Ovary & $1065(3.88)$ \\
10 & C23 Gall bladder & $911(3.31)$ \\
\hline
\end{tabular}

\section{Discussion}

The present analysis was based on a total of 27,483 new cancer cases diagnosed in Nepal from 12 hospitals from 2013 to 2015. Cases reported in 2015 ( $\mathrm{n}=9718$ ) was $11 \%$ higher than that in $2013(\mathrm{n}=8729)$. NCRP Nepal data shows an increased incidence of cancer in Nepal from 2013 (ASIR=39.1 per 100,000) to 2015 $(A S I R=41.8$ per 100,000$)$. It has been estimated by WHO that the incidence for the year 2018 to be 18.1 million cases globally which in 2040 will increase to 29.9 million [1]. Increase in life expectancy, changes in lifestyle related factors like diet, physical activity, sexual habit, environmental pollution due to industrialization might boost up in increasing the cancer incidence in Nepal. The incidence of cancer was observed to be increasing with age. Advancing age is one of the important risk factors for the overall cancer. The duration of exposure to multiple risk factors like chronic infection, unhealthy lifestyle involving tobacco and alcohol use, stress, lack of regular physical activity and poor dietary pattern, obesity, increases with advancing age [12].

The study highlights that female occupies more cancer burden than the male. The reason might be among the top 10 cancers in Nepal, the female site-specific cancer i.e cervical, breast and ovary occupy the major portion. In addition, this study showed females were affected at an earlier age than the males with age group 45-64 years being the commonest. Lung cancer was the most common cancer in men in Nepal, followed by lip/oral cavity, stomach and colorectal cancers. Cervical and breast cancers were the most common cancer in female followed by lung, ovary and stomach cancers. This trend of cancer was found to be similar to the trend in 2002 to 2012 NCRP report [6]. Thus, lung cancer, cervical cancer, breast cancer, stomach cancer, colorectal cancer and oral cancers are major cancer burden of the country. Province 3 occupies higher burden of cancer and Province 6 and 7 the least [13]. The reason might be the availability of health facilities and diagnostic centres and also the socio-economic status. Kathmandu, the capital city of Nepal is located in Province 3 and comprised of many tertiary health institutions as well as the diagnostic centres [14]. In contrast, Province 6 and 7 have less number of diagnostic facilities for cancer and the people are socio-economically weak. Thus, many will not be diagnosed and missed in the cancer registry.

Lung cancer is the leading cause of cancer in Nepal and throughout the world. The incidence of oral cancer 
Table 3. Top 10 Cancers among the Male and Female Population in Nepal 2013-2015

\begin{tabular}{llclc}
\hline S.N & Top Male Cancers & $\mathrm{n}(\%)$ & Top Female Cancers & $\mathrm{n}(\%)$ \\
\hline 1 & C33-34 Lung & $2121(16.96)$ & C53 Cervix uteri & $2552(17.04)$ \\
2 & C00-06 Lip, oral cavity & $1047(8.37)$ & C50 Breast & $2392(15.97)$ \\
3 & C16 Stomach & $909(7.27)$ & C33-34 Lung & $1616(10.79)$ \\
4 & C18-21 Colorectal & $812(6.49)$ & C56 Ovary & $1065(7.11)$ \\
5 & C91-95 Leukemia & $773(6.18)$ & C16 Stomach & $665(4.44)$ \\
6 & C32 Larynx & $751(6.00)$ & C18-21 Colorectal & $645(4.31)$ \\
7 & C67 Bladder & $547(4.37)$ & C23 Gall bladder & $616(4.11)$ \\
8 & C70-72 Brain and CNS & $419(3.35)$ & C91-95 Leukemia & $486(3.25)$ \\
9 & C22 Liver & $374(2.99)$ & C73 Thyroid & $414(2.76)$ \\
10 & C85 Non-Hodgkin Lymphoma & $353(2.82)$ & C00-06 Lip, oral cavity & $379(2.53)$ \\
\hline
\end{tabular}

Table 4. Distribution of Cancer Cases by Age Group and Gender

\begin{tabular}{lccccccccc}
\hline $\begin{array}{l}\text { Age group } \\
\text { (years) }\end{array}$ & 2013 & Male & & & Female & \multicolumn{3}{c}{ Total } \\
\hline $0-4$ & 60 & 48 & 114 & 27 & 36 & 55 & 87 & 84 & 169 \\
$5-9$ & 64 & 61 & 116 & 32 & 42 & 66 & 96 & 103 & 182 \\
$10-14$ & 71 & 89 & 110 & 66 & 47 & 64 & 137 & 136 & 174 \\
$15-19$ & 69 & 88 & 89 & 77 & 67 & 87 & 146 & 155 & 176 \\
$20-24$ & 100 & 85 & 111 & 97 & 111 & 117 & 197 & 196 & 228 \\
$25-29$ & 90 & 88 & 124 & 139 & 166 & 139 & 229 & 254 & 263 \\
$30-34$ & 144 & 140 & 149 & 195 & 234 & 212 & 339 & 374 & 361 \\
$35-39$ & 162 & 146 & 188 & 325 & 309 & 331 & 487 & 455 & 519 \\
$40-44$ & 209 & 228 & 241 & 444 & 486 & 505 & 653 & 714 & 746 \\
$45-49$ & 225 & 249 & 263 & 575 & 584 & 588 & 800 & 833 & 851 \\
$50-54$ & 328 & 379 & 433 & 563 & 627 & 641 & 891 & 1006 & 1074 \\
$55-59$ & 438 & 450 & 419 & 503 & 603 & 605 & 941 & 1053 & 1024 \\
$60-64$ & 495 & 554 & 595 & 556 & 596 & 649 & 1051 & 1150 & 1244 \\
$65-69$ & 448 & 458 & 500 & 407 & 457 & 503 & 855 & 915 & 1003 \\
$70-74$ & 649 & 504 & 498 & 448 & 355 & 369 & 1097 & 859 & 867 \\
$75-79$ & 248 & 269 & 295 & 148 & 166 & 190 & 396 & 435 & 485 \\
$80+$ & 211 & 178 & 238 & 116 & 136 & 114 & 327 & 314 & 352 \\
Total & 4,011 & 4,014 & 4,483 & 4,718 & 5,022 & 5,235 & 8729 & 9036 & 9718 \\
\hline & & & & & & & & 2014 \\
\hline
\end{tabular}

is increasing in both men and women ranking the second highest cancer among men and $10^{\text {th }}$ in women. Both these cancers are attributed to increased exposure to any form of tobacco i.e chewing and smoking [15]. According to STEPS Survey Nepal, tobacco smoking proportion in Nepalese population is $18.5 \%$ (men $27.0 \%$ and women $10.3 \%$ ) and for smokeless tobacco use it is $17.8 \%$ (men $31.3 \%$ and women $4.8 \%$ ) [16]. The government of Nepal has undertaken a number of tobacco control initiatives which includes most of the important provisions of the Framework Convention, i.e. prohibition of smoking in public places, on public transport and in workplaces; ban on all forms of tobacco advertisement, promotion and sponsorship; pictorial health warnings in cigarette, bidi and other tobacco packets; prohibition of sale of tobacco to and by minors and pregnant women; establishment of a tobacco control and regulatory committee; establishment of a health tax fund, etc. [17-18]. Although tobacco control legislation and policies exist in Nepal, they have to be implemented effectively.

Over the year, cervix and breast cancers have increased in Nepal. Creating awareness on cervical cancer, vaccination against HPV and regular screening for cervical cancer help in early detection and prevention of cervical cancer [19]. Similarly, regular self-examination, periodic clinical breast examination and mammogram are excellent ways of detection of early stage of breast cancer [20]. Despite being early detectable and curable cancers in Nepal, most of the women are diagnosed at late stage [21]. Thus, raising awareness among women on these cancers along with nationwide screening campaigns would aid in early detection and treatment thereby reducing the morbidity and mortality caused by 
Table 5. Crude Age Specific Incidence Rate per 100,000 Population in 2013-2015

\begin{tabular}{lccccccccc}
\hline $\begin{array}{l}\text { Age group } \\
\text { (years) }\end{array}$ & 2013 & 2014 & 2015 & 2013 & 2014 & 2015 & 2013 & 2014 & 2015 \\
\hline $0-4$ & 4.204 & 3.295 & 7.651 & 1.998 & 2.664 & 3.935 & 3.131 & 2.968 & 5.852 \\
$5-9$ & 4.367 & 4.279 & 8.326 & 2.283 & 2.996 & 4.961 & 3.348 & 3.694 & 6.682 \\
$10-14$ & 4.253 & 5.432 & 6.866 & 4.112 & 2.928 & 4.166 & 4.184 & 4.236 & 5.545 \\
$15-19$ & 4.261 & 5.324 & 5.319 & 4.772 & 4.152 & 5.307 & 4.516 & 4.719 & 5.313 \\
$20-24$ & 8.172 & 6.466 & 7.919 & 6.869 & 7.86 & 7.769 & 7.474 & 7.062 & 7.841 \\
$25-29$ & 9.741 & 9.294 & 12.626 & 11.484 & 13.714 & 10.94 & 10.73 & 11.622 & 11.675 \\
$30-34$ & 17.563 & 16.825 & 17.625 & 18.685 & 22.422 & 19.143 & 18.191 & 19.605 & 18.486 \\
$35-39$ & 22.034 & 19.525 & 24.73 & 36.428 & 34.635 & 35.15 & 29.925 & 27.343 & 30.496 \\
$40-44$ & 31.206 & 33.727 & 35.289 & 58.325 & 63.842 & 62.545 & 45.632 & 48.898 & 50.055 \\
$45-49$ & 37.334 & 40.594 & 42.197 & 89.255 & 90.652 & 86.228 & 64.16 & 65.27 & 65.201 \\
$50-54$ & 63.413 & 71.623 & 80.017 & 107.007 & 119.171 & 112.997 & 85.396 & 93.515 & 96.896 \\
$55-59$ & 100.091 & 101.095 & 92.41 & 116.565 & 139.739 & 133.264 & 108.27 & 118.724 & 112.85 \\
$60-64$ & 136.148 & 149.865 & 158.199 & 149.81 & 160.588 & 170.359 & 143.049 & 154.293 & 164.318 \\
$65-69$ & 152.479 & 154.604 & 166.957 & 131.477 & 147.629 & 157.241 & 141.704 & 149.766 & 161.939 \\
$70-74$ & 271.093 & 213.568 & 214.017 & 177.221 & 140.432 & 147 & 222.881 & 176.038 & 179.239 \\
$75-79$ & 181.788 & 180.207 & 186.985 & 105.314 & 118.123 & 111.69 & 142.984 & 141.709 & 147.92 \\
$80+$ & 295.854 & 242.606 & 303.703 & 156.918 & 183.973 & 137.387 & 225.14 & 209.377 & 218.169 \\
Total & 30.35 & 29.948 & 32.98 & 33.6 & 35.765 & 36.241 & 32.024 & 32.685 & 34.66 \\
\hline & & & & & & & & & \\
\hline
\end{tabular}

these female-related cancers [22-23].

Stomach, colorectal, oesophagus, gall bladder and liver are also rising cancers in Nepal. The dietary factors like consumption of alcohol, food at very high temperature, fatty junk food, spicy food, low fiber diet, processed meat and red meat and salt preserved foods are the key risk factors for these cancers in Nepal [12].

The overall incidence of cancer in Nepal is in steady rise among both males and females, becoming a major public health problem. This challenges the overall health system of the country in present as well as in near future. Strengthening health system of the country from periphery to tertiary level in cancer prevention, early detection, diagnosis, treatment and palliation is way forward to cope with this rising incidence of cancer. Incorporating cancer control activities in package of essential non-communicable disease (PEN) program would be a significant step towards its prevention. Also, nationwide intervention on control of tobacco consumption would be a cost-effective cancer prevention activity. Furthermore, the top cancers in Nepal i.e. cervical cancer, breast cancer and oral cancer are early detectable and curable, nationwide extensive screening programs, awareness activities, launching HPV vaccination in National immunization program to reduce the load of these cancers.

The major limitation of our study is that NCRP data collection does not cover patients who are diagnosed and treated elsewhere than the 12 included hospitals. However, these hospitals are the major cancer treatment centres with good coverage of the country. Our findings may serve as a baseline for future comparisons and assessment of the overall effectiveness of cancer health care in Nepal and may provide a clue to capture the greatest need.
In conclusion, the incidence of cancer is in increasing trend in Nepal with lung, cervix, breast, stomach and colorectal cancers being the leading cancer sites. This study reflects that cancer is a key public health issue of the current era and the government should focus on all the aspects of cancer control i.e., preventive, curative and rehabilitative services.

\section{Acknowledgements}

The authors would like to express their gratitude to the National Cancer Registry Program for providing data to conduct this study.

\section{Funding Statement None}

Statement Conflict of Interest

None

\section{References}

1. GLOBOCAN. New global cancer data: GLOBOCAN 2018 [Online]. Lyon, France: International Agency for Research on Cancer, World Health Organization, 2018. Available: https://www.uicc.org/new-global-cancer-dataglobocan-2018 [Accessed 12 March 2019]..

2. Aly H. Dietary habits and relation to cancer disease in different population . Arch Cancer Res. 2012;1(1).

3. Bloom D, Cafiero E, Jané-Llopis E, Abrahams-Gessel S, Bloom L, Fathima S, et. al. The global economic burden of noncommunicable diseases. Program on the Global Demography of Aging; 2012 [Online].Geneva: World Economic Forum and Harvard School of Public Health. Available: http://www3.weforum.org/docs/WEF_Harvard_ 
HE lobalEconomicBurdenNonCommunicableDiseases 20 11pdf [Accessed Feb 2 2019].

4. GLOBOCAN. The global cancer observatory: Nepal factsheet [Online]. Lyon, France: International Agency for Research on Cancer, World Health Organization, 2018. Available: http://gco.iarc.fr/today/data/factsheets/populations/524nepal-fact-sheets.pdf [Accessed Feb 18 2019..

5. Poudel K, Huang Z, Neupane PR, Steel R. Prediction of the Cancer Incidence in Nepal. Asian Pacific Journal of Cancer Prevention. 2017 01;18(1). https://doi.org/10.22034/ APJCP.2017.18.1.165

6. National Cancer Registry Program. Hospital based cancer registry 10 years consolidated report (2003-2012). Bharatpur, Chitwan, Nepal: Department of Cancer Prevention, Control and Research, B.P. Koirala Memorial Cancer Hospital, 2015.

7. Shrestha G, Pradhananga K, Mulmi R, Subedi K, Siwakoti B. Cancer registration in Nepal: current status and way forward. JNMA J Nepal Med Assoc. 2019;58(216).

8. National Cancer Registry Program. Report of hospital based cancer registry 2013. Bharatpur, Chitwan, Nepal: Department of Cancer Prevention, Control and Research, B.P. Koirala Memorial Cancer Hospital, 2016.

9. National Cancer Registry Program. Report of hospital based cancer registry 2014. Bharatpur, Chitwan, Nepal: Department of Cancer Prevention, Control and Research, B.P. Koirala Memorial Cancer Hospital, 2017.

10. National Cancer Registry Program. Report of hospital based cancer registry 2015. Bharatpur, Chitwan, Nepal: Department of Cancer Prevention, Control and Research, B.P. Koirala Memorial Cancer Hospital, 2018.

11. Central Bureau of Statistics. National population and housing census 2011 (population projection 2011 - 2031) [Online]. Kathmandu, Nepal: Central Bureau of Statistics, 2014. Available: https://cbs.gov.np/wp-content/upLoads/2018/12/ PopulationProjection2011-2031.pdf [Accessed Nov 1 2018].

12. Kushi LH, Doyle C, McCullough M, Rock CL, DemarkWahnefried W, Bandera EV, Gapstur S, Patel AV, Andrews $\mathrm{K}$, Gansler T, . American Cancer Society guidelines on nutrition and physical activity for cancer prevention. CA: A Cancer Journal for Clinicians. 2012 01;62(1):30-67. https:// doi.org/10.3322/caac. 20140

13. MoHP, New ERA, ICF. Nepal demographic and health survey 2016 [Online]. Kathmandu, Nepal: Ministry of Health, Government of Nepal, 2017. Available: https:// www.dhsprogram.com/pubs/pdf/fr336/fr336.pdf [Accessed Jan 18 2018].

14. Adhikari S. Cancer burden in Nepal: a call for action. MOJ Proteomics \& Bioinformatics. 201809 21;7(5). https://doi. org/10.15406/mojpb.2018.07.00247

15. Danaei G, Vander Hoorn S, Lopez AD, Murray CJ, Ezzati M. Causes of cancer in the world: comparative risk assessment of nine behavioural and environmental risk factors. The Lancet. 2005 Nov;366(9499):1784-1793. https://doi. org/10.1016/s0140-6736(05)67725-2

16. Aryal K, Neupane S, Mehata S, Vaidhya A, Singh S, Paulin $\mathrm{P}$, et al. Non communicable diseases risk factors: STEPS survey Nepal 2013 [Online]. Kathmandu, Nepal: Nepal Health Research Council, 2014. Available: http://nhrc.gov. np/wp-content/uploads/2017/02/noncommunicable-diseasereport_2012_2013.pdf [Accessed Dec 12 2018].

17. Nepal Law Commission. Tobacco products (control and regulatory) act, 2068 (2011) [Online]. Kathmandu, Nepal: Nepal Law Commission, Government of Nepal, 2011. Available: http://www.lawcommission.gov.np/en/ archives/19086 [Accessed Feb 2 2019].
18. MoHP. Brief profile on tobacco control in Nepal [Online]. Kathmandu, Nepal: Ministry of Health and Population, Government of Nepal, 2012. Available: https://www.who.int/ fctc/reporting/party_reports/nepal_2012_annex2_tobacco_ profile.pdf [Accessed March 10 2019].

19. Saslow D, Solomon D, Lawson HW, Killackey M, Kulasingam SL, Cain J, Garcia FAR, Moriarty AT, Waxman AG, Wilbur DC, Wentzensen N, Downs LS, Spitzer M, Moscicki A, Franco EL, Stoler MH, Schiffman M, Castle PE, Myers ER, . American Cancer Society, American Society for Colposcopy and Cervical Pathology, and American Society for Clinical Pathology screening guidelines for the prevention and early detection of cervical cancer. CA: A Cancer Journal for Clinicians. 201203 14;62(3):147-172. https://doi.org/10.3322/caac.21139

20. Smith RA, Saslow D, Andrews Sawyer K, Burke W, Costanza ME, Evans WP, Foster RS, Hendrick E, Eyre HJ, Sener S. American Cancer Society Guidelines for Breast Cancer Screening: Update 2003. CA: A Cancer Journal for Clinicians. 200305 01;53(3):141-169. https://doi. org/10.3322/canjclin.53.3.141

21. Gyenwali D, Pariyar J, Onta SR. Factors Associated with Late Diagnosis of Cervical Cancer in Nepal. Asian Pacific Journal of Cancer Prevention. 201307 30;14(7):4373-4377. https://doi.org/10.7314/apjcp.2013.14.7.4373

22. Gyenwali D, Khanal G, Paudel R, Amatya A, Pariyar J, Onta SR. Estimates of delays in diagnosis of cervical cancer in Nepal. BMC Women's Health. 201402 17;14(1). https:// doi.org/10.1186/1472-6874-14-29

23. Giri M, Giri M, Thapa RJ, Upreti B, Pariyar B. Breast Cancer in Nepal: Current status and future directions (Review). Biomedical Reports. 201802 05; 8(4):325-329. https://doi. org/10.3892/br.2018.1057

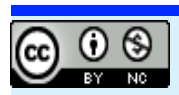

This work is licensed under a Creative Commons AttributionNon Commercial 4.0 International License. 